sach răng sẽ giúp làm giảm đáng kể mức độ mảng bám và viêm lợi cho bệnh nhân chỉnh nha.

Bảng 5 cho thấy có mối liên quan giữa mức độ viêm lợi và khoảng thời gian lấy cao răng định kỳ gần nhất. Kết quả này cũng tương đồng với báo cáo của Mahindra RK và cS, tỉ lệ viêm lợi tăng lên đáng kể ở nhóm $B N$ chỉnh nha mà không đến khám vệ sinh răng miệng trong quá trình điều trị? Còn mảng bám răng được hình thành và tích lũy hàng ngày, phụ thuộc vào thói quen, tần suất, cách thức vệ sinh răng miệng chứ không phụ thuộc vào việc lấy cao răng trước đó.

Kết quả ở bảng 6 cho thấy thời gian đeo mắc cài không ảnh hưởng đến mức độ viêm lợi của $B N$. Có thể nói, mức độ mảng bám răng và viêm Iợi phụ thuộc vào ý thức, cách thức, tần suất vệ sinh răng miệng của $B N$ mà không phụ thuộc vào thời gian chỉnh nha của $\mathrm{BN}$. Ở những $\mathrm{BN}$ có thời gian chỉnh nha kéo dài, nếu $B N$ vẫn duy trì được việc vệ sinh răng miệng hàng ngày và định kỳ thì sẽ có thể duy trì được chỉ số lợi và mảng bám ở mức tốt.

\section{KẾT LUẬN}

- Không có sự khác biệtvề tình trạng viêm lợi giữa nam và nữ trong nhóm nghiên cứu .

- Mức độ viêm lợi ở lứa tuổi dưới 18 nặng hơn so với lứa tuổi trên 18.

- Ở bệnh nhân đeo mắc cài chỉnh nha, tình trạng viêm lợi có liên quan đến số lần chải răng trong ngày, thói quen dùng các biện pháp hỗ trợ làm sạch răng, khoảng thời gian lấy cao răng định kỳ gần nhất, nhưng không liên quan đến thời gian đeo mắc cài.

\section{TÀI LIÊU THAM KHẢO}

1. Contaldo $\mathbf{M}$, Lucchese $A$, Lajolo $\mathbf{C}$, et al. The Oral Microbiota Changes in Orthodontic Patients and Effects on Oral Health: An Overview. Journal of Clinical Medicine. 2021;10(4):780. doi:10.3390/jcm10040780

2. Mahindra RK, Suryawanshi GR, Doshi UH. Effects of fixed orthodontic treatment on gingival health: An observational study. International Journal of Applied Dental Sciences.:6.

3. Nha Khoa Cộng Đồng. Vol 1. Nhà xuất bản Giáo dục Việt Nam; 2016.

4. Rakhshan $\mathbf{H}$, Rakhshan V. Effects of the initia stage of active fixed orthodontic treatment and sex on dental plaque accumulation: A preliminary prospective cohort study. The Saudi Journal for Dental Research. 2015;6(2):86-90. doi:10.1016/j.sjdr.2014.09.001

5. Akkaya M. Are the Effects of Fixed Orthodontic Treatment on Gingival Health Similar in Adolescents and Young Adults? Journal of Biomedical Sciences. 2016;6(1):5.

6. Tevatia S. Puberty Induced Gingival Enlargement. BJSTR. $2017 ; 1(1)$ doi:10.26717/BJSTR.2017.01.000126

7. $\mathbf{R}$ MD la $\mathbf{R}$, Guerra JZ, Johnston DA, Radike AW. Plaque Growth and Removal With Daily Toothbrushing. Journal of Periodontology. 1979;50(12):661-664.

doi:10.1902/jop.1979.50.12.661

\title{
KẾT QUẢ PHẪU THUÂT TAQO HÌNH NƠ VI HẮC TỐ BẨM SINH VÙNG MẶT Cổ
}

\section{Chanthavy Souksavarn*, Trần Thiết Sơn,* Tạ Thị Hồng Thúy*, Dương Đại Hà*}

\section{TÓM TẮT}

Bài báo nhằm đánh giá kết quả phẫu thuật tạo hình nơ vi hắc tố bẩm sinh vùng mặt cổ. Nghiên cựu trên 36 bệnh nhân (16 nam và 20 nữ̛) với 45 lần phẫu thuật từ 1/2015 đến 5/2020 tại khoa Phẫu thuật tạo hình - Bệnh viện Xanh Pôn Hà Nội. Kết quả cho thấy đặc điểm nơ vi hắc tố bẩm sinh vùng mặt cổ rấtđa dạng về kích thước, vịtrí. Nơ vi kích thước nhỏ hay găp nhất $(76,2 \%)$, trung bình $(14,3 \%)$, kích thước lớn $(9,5 \%)$. 26/36 bệnh nhân $(72,2 \%)$ đã được lấy bỏ

*Trường Đại học Y Hà Nội.

Chịu trách nhiệm chính: Chanthavy Souksavarn.

Email: c.souksavarn@gmail.com

Ngày nhận bài: 10/7/2021

Ngày phản biên khoa học: 7/8/2021

Ngày duyệt bài: 25/8/2021 hoàn toàn thường bằng kỹ thuât giãn da tự nhiên đối với no vi kích thước nhỏ và trung bình, nơ vi kích thước lớn phải phẫu thuật nhiều lần. Bệnh nhân phẫu thuât 1 lần $29 / 36$ nơ vì $(80,5 \%), 2$ lần $5 / 36$ nơ vì $(13,8 \%), 3$ lần $2 / 36$ nơ vi $(5,7 \%)$. Phương pháp tạo hình giãn da tự nhiên 40/54 lần phẫu thuật (70\%) các vạt tại chỗ $7 / 54(12,9 \%)$, ghép da dày $5 / 54$ $(9,8 \%)$, vạt lân cân và vat tổ chứcgiãn chiếm tỉ lế ít hơn. Kễt quả gần tốt $(8 \dot{6}, 7 \%)$, trung bình $(13,3 \%)$. Sau phẫu thuật 3-6 tháng, kết quả tốt $86,1 \%$, trung bình $13,9 \%$ và không có trường hợp nào kết quả kém. Biến chứng chủ yếu seo lồi $6 / 36(5,5 \%)$, co kéo vùng mặt với mức độ nhẹ 6/36 (5,5\%). Như vậy, giãn da tự nhiên là một trong những kỹ thuật đơn giản, hiệu quả áp dụng nhiều vùng mặt cô. Kỹ thuật vạt hay giãn da ít được sử dụng hơn và thường dùng với những tổn thương lớn và nhiều đơn vị. Tư khóa: Nỡ vi hắc tố bẩm sinh, cắt u, giãn da tự nhiên, vạt tại chỗ. 


\section{SUMMARY \\ OUTCOMES OF SURGICAL MANAGEMENT IN PATIENTS WITH CONGENITAL \\ MELANOCYSTIC NEVI ON FACE AND NECK}

This article aims to evaluate the results out come of congenital melanocystic nevi surgery in the face and neck area, Thirty-six patients were reviewed (16 males and 20 females) with 45 surgeries between Juanry 2015 to May 2020 at the Department of Plastic Surgery - Saint Paul Hospital Hanoi. The results showed that the characteristics of melanocystic nevi in the face and neck were very diverse in size and position. Small size was most common (76.2\%), medium $(14.3 \%)$, largesize $(9.5 \%)$. In $26 / 36$ patients $(72.2 \%)$ small and medium size nevi were completely removed with natural skin dilation technique, large sized nevi required multiple surgeries. 29/36 nevi $(80.5 \%)$ were removed in single reconstructive stage, $5 / 36$ nevi $(13,8 \%)$ were removed in 2 reconstructive stages, only $2 / 36$ nevi $(5.7 \%)$ were removed in 3 reconstructive stages. Serial excision was used $40 / 54$ times $(70 \%)$, also local flap was used $7 / 45$ times $(12.9 \%)$, and $5 / 54$ of full thickness skin graft was used, the neighboring flap and tissue expansion had a smaller ratio of usage. The results were close to be good in $(86.7 \%)$ of cases, average in (13.3\%) of cases, After lesions were completely removed for 3-6 months, the results were good in $86.1 \%$ of cases, average in $13.9 \%$ of cases and no cases of poor results. The main complications result in keloid scars for $6 / 36(5.5 \%)$, while mild facial retraction occurred in $6 / 36(5.5 \%)$. Thus, Serial excision is one of the most simple and effective techniques that can be applied to many area of face and neck, while flap and tissue expansion are less commonly used with large lesions and multiple units.

Keywords: Congenital melanocytic nevi, mass removal, serial excision, local flap.

\section{I. ĐẶT VẤN ĐỀ}

Nơ vi hắc tố bẩm sinhtrong tiếng Anh là Congenital melanocytic nevi (CMN) là nơ vi hắc tố xuất hiện lúc sinh hoặc trong vòng hai đến ba năm đầu đời, kết quả của sự tăng sinh lành tính của tế bào nơ vi-một loại tể bào có cùng nguồn gốc từ đỉnh thần kinh giống như tế bào hắc tố (melanocyte). Nơ vi hắc tố bẩm sinh là một tổn thương khá phổ biến, gặp ở khoảng từ 1-6\% trẻ mới sinh ${ }^{1}$. Tất cả các nơ vi hắc tố bẩm sinh đều có nguy cơ chuyển dạng thành ung thư hắc tố, tỷ lệ này cao hơn ở nơ vi kích thước lớn. Hơn nữa nơ vi ở các vị trí da hở, gây mất thẩm mỹ như vùng mặt. Ngoài ra, còn gây ảnh hưởng tới tâm lý bệnh nhân và gia đình. Trong đó mặt cổ là vùng được quan tâm nhất, với tỉ lệ bệnh nhân đến khám nhiều nhất ${ }^{2}$. Hai vấn đề chính đó đưa ra các chỉ định điều trị CNM vùng mặt cổ là nguy cơ ung thư hóa và ảnhhưởng thẩm mỹ. Phương pháp phẫu thuật điều trị là giải pháp tối ưu nhất có thể quyết được cả hai vấn đề này. Có nhiều phương pháp điều trị nơ vi hắc tố bẩm sinh bao gồm các phương pháp không phẫu thuật và phẫu thuật. Các phương pháp không phẫu thuật gồm có nạo da (curettage), mài da (dermabrasion), lột da bằng hóa chất (chemical peel), đốt diện (electrosurgery), đốt Laser... Nhưng nhược điểm của các phương pháp này chì loại bỏ một phần tế bào của nơ vi nên ít làm thay đổi nguy cơ ung thư hóa. Vì vậy, Phương pháp phẫu thuật có thể cắt bỏ hết tể bào nơ vì được.Phẫu thuẩt với muc đích cắt bỏ thương tổn (cắt một thì hoặc nhiều thi) và xử lý che phủ khuyết da (đóng trực tiếp, phẫu thuật cắt thu nhiều lân, sử dụng vạt kế cận, ghép da, vạt tổ chức giãn hoă̆c các vạt từ xa). Trên thế giới này có nhiều nghiên cứu về nơ vi hắc tố bẩm sinh. Ơ Việt Nam đã có một số nghiên cứu về nơ vi hắc tố bẩm sinh. Đỗ Đình Thuận ${ }^{3}$ (1998) nghiên cứu về đắc điểm lâm sàng và phương pháp điều trị nơ vi sắc tố lành tính vùng hàm mặt bao gồm cả nơ vi bẩm sinh và mắc phải, Nguyễn Hồng Sơn ${ }^{4}$ (2010) nghiên cứu về đặc điểm lâm sàng và đánh giá kết quả điều trị nơ vi sắc tố bẩm sinh khổng lồ. Tuy nhiên chưa có nghiên cứu nào nói riêng về vùng mặt cổ. Khi nào thì điều trị bằng các phương pháp phẫu thuật tạo hình nào cho thích hợp? Kết quả điều trị của các phương pháp đó như thế nào? Vì vậy, chúng tôi thực hiện nghiên cứu này với mục tiêu: Đánh giá kêt quả phẫu thuật tạo hinh nơ vi hắc tố bẩm sinh vưng măt cô.

\section{II. ĐỐI TƯƠNG VÀ PHƯƠNG PHÁP NGHIÊN CỨU}

2.1. Đối tượng nghiên cứu. Bao gồm 36 bệnh nhân gồm 16 nam và 22 nữ được chẩn đoán nơ vi hắc tố bẩm sinh vùng mặt cổ được thực hiện phẫu thuật tại khoa Phẩu Thuật Tạo Hình-Thẩm Mỹ Bệnh Viện Đa Khoa Xanh pôn Hà Nội.Thờigian từ tháng 01/2015 đến 05/2020.

\subsection{Phương pháp nghiên cứu}

Phương pháp nghiên cứu là hồi cứu mô tả lâm sàng không đối chứng.

*Tiêu chuấn lưa chon: Tất cả bênh nhân được chẩn đoán nơ vi hắc tố bẩm sinh vùng mặt cổ được can thiệp phẩu thuật, đầy đủ hồ sơ bệnh án, đầy đủ hình ảnh trước, trong và sau mổ.

*Tiêu chuẩn loai trừ: Mất hồ sơ bệnh án, không đủ thông tin dừ liệu.

Quy trình nghiên cứu dựa vào hồ sơ ghi chép tî mỉ với nguyên tắc cắt nơ vi sắc tố sử dùng phương pháp tạo hình và được lưu trử bằng hình ảnh chi tiết qua từng giai đoạn.

2.3. Các bước thực hành phẫu thuật 
2.3.1. Lập kế hoạch phẩu thuật. Dựa trên tổn thương theo phân tích và lựa chọn phương pháp phẫu thuật, thiết kế và lựa chọn kỹ thuật trước mổ.

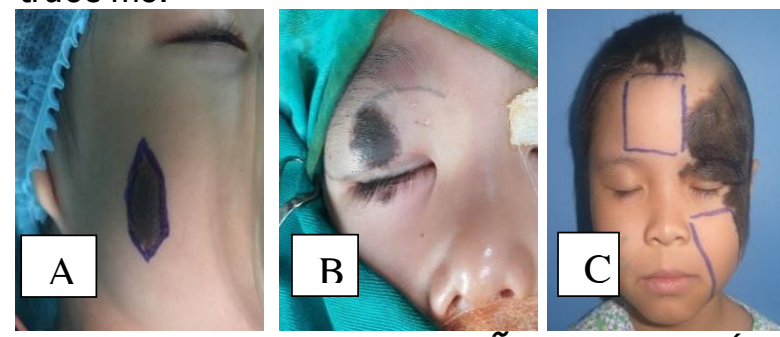

Hình 1. Thiết kếtrước phẫu thuât. A. Cắt đóng trức tiếp. B. vạt tai chố. C. Vị trí đặt túi giãn da.

2.3.2. Các bước phẫu thuật. Tiến hành gây mê nội khí quản hoặc gây tê tại chỗ đối với nơ vi nhỏ và bệnh nhân hợp tác.

- Kỹ thuật giãn da tự nhiên: Cắt bỏ tổn thương theo thiết kế, khâu đóng tổn thương trực tiếp nhờ đặc tính chun giãn của da.

- Kỹ thuât vạt tai chỗ, vạt lân cận: Rạch da theo thiết kể vạt, bóc tác vạt, cắt bỏ thương tổn, sử dụng dưới dạng vạt chuyển, xoay hoặc đặt chẽ phủ tổn khuyết.

- Kỹ thuâat ghép da dày: Lấy da dày toàn bộ ghép vào tổn thương như mi mắt, một số trường hợp vùng trán , mũi.

- Kỹ thuật đặt hệ thống giãn da: Gồm phẫu thuật lần một đặt túi giãn da ngay vị trí tổn thương vùng má, cổ hoặc trán, bơm túi giãn sau 2-3 tháng, phẫu thuật lần 2 tháo túi, tạo hình che phủ thương tổn.

- Một số trường hợp phải phối hợp nhiều kỹ thuật.

2.3.3. Theo dõi sau mổ và đánh giá kết quả sau mổ:

- Sau mổ đánh giá kết quả: tình trạng vết mổ, khả năng liền thương, sức sống của vạt, biến chứng sớm (tụ máu, nhiễm trùng, thiếu dưỡng vạt, hoại tử vạt).

- Kết quả xa (3-6 tháng sau mổ): đánh giá tình trạng sẹo, co kéo cơ quan, mức độ còn khối nơ vi, mức độ hài lòng.

Bảng 1. Thang điểm đánh giá kêt quả điều trị xa (sau3-6 tháng)

\begin{tabular}{|c|c|c|c|}
\hline $\begin{array}{c}\text { Tình trạng } \\
\text { sẹo }\end{array}$ & $\begin{array}{c}\text { Lồi, quám } \\
\text { phát }\end{array}$ & $\begin{array}{c}\mathbf{1} \text { Giãn }>2 \mathrm{~m} \\
\mathrm{~m}\end{array}$ & $\mathbf{2}$ điếm \\
\hline $\begin{array}{c}\text { Co kéo hốc } \\
\text { tự nhiên }\end{array}$ & Nhiều & Ít & Không co kéo \\
\hline $\begin{array}{c}\text { Nớ vi sau } \\
\text { cắt bỏ }\end{array}$ & Còn nhiều & Còn ít & $\begin{array}{c}\text { Hết hoàn } \\
\text { toàn }\end{array}$ \\
\hline Mức độ hài & Kém hài & Trung & Nhiêu \\
\hline
\end{tabular}

\begin{tabular}{|c|c|c|c|}
\hline lòng & lòng & bình & \\
\hline Xếp loại kết quả xa: tốt (7-8 điểm), trung
\end{tabular} bình (4-6 điểm), kém (0-3 điểm).

\section{KẾT QUẢ NGHIÊN CỨU}

Trong 36 bệnh nhân nghiên cứu có 16 nam $(44,4 \%)$ và 20 nữ $(55,6 \%)$. Độ tuổi trung bình là 8,97 tuổi. 24/36 bệnh nhân $(66,6 \%)$ chỉ có CMN nằm trên một đơn vi giải phẫu vùng mặt cổ, 12/36 bệnh nhân có $\mathrm{CMN}$ nằm trên2 đơn vị giải phẫu vùng mặt cổ (33,4\%). Trong 36 bệnh nhận, có nơ vi xuất hiện gồm 61 đơn vị giải phẫu vùng mặt cổ.

Bảng 2. Các đặc điểm của CMN vùng mặt cổ

\begin{tabular}{|c|c|c|c|}
\hline \multicolumn{2}{|c|}{ Đặc điểm } & Số CMN & Tỉ lệ (\%) \\
\hline \multirow{3}{*}{$\begin{array}{c}\text { Kích thước }(\mathrm{cm}) \\
(\mathrm{N}=42)\end{array}$} & $\leq 3 \mathrm{~cm}$ & 32 & 76,2 \\
\hline & $3-12 \mathrm{~cm}$ & 06 & 14,3 \\
\hline & $\geq 12 \mathrm{~cm}$ & 04 & 9,5 \\
\hline \multirow{9}{*}{$\begin{array}{l}\text { Vị trí nơ vi } \\
(\mathrm{N}=61)\end{array}$} & Trán & 08 & 13,1 \\
\hline & Mũi & 05 & 8,1 \\
\hline & Mắt & 08 & 13,1 \\
\hline & Má & 24 & 39,3 \\
\hline & Môi trên & 05 & 8,1 \\
\hline & Môi dưới & 04 & 6,5 \\
\hline & Cằm & 03 & 4,9 \\
\hline & Tai & 02 & 3,2 \\
\hline & Cố & 02 & 3,2 \\
\hline \multirow{2}{*}{$\begin{array}{l}\text { Chiếm số đơn } \\
\text { vị giải phẫu } \\
\text { vùng mặt } \\
(n=36)\end{array}$} & 1 đơn vị & 24 & 66,6 \\
\hline & $\begin{array}{l}\geq 2 \text { đơn } \\
\text { vị }\end{array}$ & 12 & 33,4 \\
\hline
\end{tabular}

Trong 36 bệnh nhân có nơ vi xuất hiện trên những các đơn vị giải phẫu thẩm mỹ vùng mặt cổ tất cả 61 đơn vị. Trong 26bệnh nhân nơ vi được cắt bỏ hết hoàn toàn chiếm $72,2 \%$ còn lại là lấy bỏ được phần lớn của nơ vi, đặc biệt là những nơ vi có kích thước lớn hay ở vị trí khó lấy hết được.

Bảng 3. Số lần phẫu thuật để loại bỏ thương tôn $(n=36)$.

\begin{tabular}{|c|c|c|}
\hline $\begin{array}{c}\text { Số lần phâu } \\
\text { thuật }\end{array}$ & $\begin{array}{c}\text { Số bệnh } \\
\text { nhân nơ vi }\end{array}$ & $\begin{array}{c}\text { Tỉ lệ̂ } \\
\text { (\%) }\end{array}$ \\
\hline 1 lần & 29 & 80,5 \\
\hline 2 lần & 5 & 13,8 \\
\hline 3 lần & 2 & 5,7 \\
\hline
\end{tabular}

Gur and Zuger ${ }^{8}$, đã đề xuất phân loại để tính số lần phẫu thuật dựa vào kích thước và đơn vi giải phẫu thẩm mỹ cùng mặt cổ theo Bảng 4. Trong nghiên cứu này nơ vi kích thước nhỏ thường chỉ cần trài qua môt lần phẫu nhưng đối với kích thước vừa và lớn thường phẫu thuật ít nhất 2 lần.

Bảng 4. Phân chia nhóm nơ vi vùng mặt cổ \begin{tabular}{|l|l|l|}
\hline Kích thước & Kích thước & Kích thước \\
\hline
\end{tabular} 


\begin{tabular}{|c|c|c|}
\hline nhỏ & vừa & lớn \\
\hline $1-3 \mathrm{~cm}$ & 3-12cm đường & $>12 \mathrm{~cm}$ \\
đường kính & kính & đường kính \\
1 đơn vi & $1-2$ đơn vi & $>2$ đơn vi \\
thẩm mỹ & thẩm mỹ & thẩm mỹ \\
1-2 lần phâ̂u & $1-2$ lần phẫu & $>2$ lần phẫu \\
thuật & thuật & thuật \\
\hline
\end{tabular}

Trong 36 bệnh nhân với 45 lần phấu thuật và sử dùng phối hợp nhiêu kỹ thuật trong 11 ca phẫu thuật (54 kỹ thuật/36 bệnh nhân), phương pháp được sử dùng nhiêu nhất là giãn da tự nhiên 40/54 (70\%), vat tai chố 7/54 (12,9\%) với dạng vạt chủ yếu là dạng đẩy, xoay. Vạt lân cận $2 / 54(3,7 \%)$ cho bệnh nhân có nơ vi vùng lông mày từ vạt động mạch thái dương nông và một bênh nhân dùng vạt Mustarder từ da vùng cổ đẩy sang che phủ vùng má phải, vạt tổ chức giãn được sử dùng 1 lần cho bệnh nhẩn có nơ vi khổng lồ nửa mặt bên trái bằng đặt 2 túi chất liệu giãn da ổ trán và má bên trái, sau đó chuyển vất giãn tố chức sang tạo hình che phủ khuyết tổn sau khi cắt nơ vi. Trong đó có 10 bệnh nhân phải sử dùng nhiều phương pháp khác nhau phối hợp chủ yếu là nơ vi nằm trên nhiêu đơn vi giải phâuu thẩm mỹ.

Bảng 5. Phân bố phương pháp tạo hình chẽ phủ $(n=54)$

\begin{tabular}{|c|c|c|}
\hline $\begin{array}{c}\text { Phương pháp tạo } \\
\text { hinh }\end{array}$ & $\begin{array}{c}\text { Số lân sử } \\
\text { dùng mối PP }\end{array}$ & Tỉ lệ \\
\hline Giãn da tụ nhiên & 40 & $70 \%$ \\
\hline Vạt tại chố & 7 & $12,9 \%$ \\
\hline Vạt lân cận & 1 & $1,8 \%$ \\
\hline Ghép da & 5 & $9,3 \%$ \\
\hline Vạt tố chức giãn & 1 & $1,8 \%$ \\
\hline Tổng & $\mathbf{5 4}$ & $\mathbf{1 0 0 \%}$ \\
\hline
\end{tabular}

Kết quả gần được theo dõi, đánh giá trong 45 lân phẫu thuật trên 36 bệnh nhân. Không trường hợp nào có biến chứng chảy máu, nhiễm trùng, hoặc hoại tử. Có $13,3 \%$ trường hợp chậm liền vết mổ, về tình trạng biến dạng gần ngay sau mổ, có $13,3 \%$ trường hợp biến dạng mức độ ít. Kết quả gần đạt tốt với 39/45 (86,7\%), đạt trung bình với $6 / 45(13,3 \%)$ trường hợp, không có trường hợp đạt kết quả kém.

Bảng 6. Kêt quả gần ( $n=45)$.

\begin{tabular}{|c|c|c|c|}
\hline \multicolumn{2}{|c|}{ Kết quả gân } & $\begin{array}{c}\text { Số lần phấy } \\
\text { thuật }\end{array}$ & $\begin{array}{c}\text { Tỉ lệ } \\
(\%)\end{array}$ \\
\hline \multirow{2}{*}{$\begin{array}{c}\text { Tình trạng } \\
\text { liền thương }\end{array}$} & Liền tốt & 39 & 86,7 \\
\cline { 2 - 4 } & Chậm liền & 6 & 13,3 \\
\hline \multirow{2}{*}{$\begin{array}{c}\text { Tính trạng } \\
\text { hoại tứ }\end{array}$} & Không có & 39 & 86,7 \\
\cline { 2 - 4 } & $\begin{array}{c}\text { Thiếu dưỡng } \\
\text { mép }\end{array}$ & 6 & 13,3 \\
\cline { 2 - 4 } & Hoại tứ & 0 & 0 \\
\hline
\end{tabular}

\begin{tabular}{|c|c|c|c|}
\hline \multirow{2}{*}{$\begin{array}{c}\text { Tình trạng } \\
\text { biến dạng } \\
\text { gần }\end{array}$} & Nhiều & 0 & 0 \\
\cline { 2 - 4 } & İt & 6 & 13,3 \\
\cline { 2 - 4 } & $\begin{array}{c}\text { Không biến } \\
\text { dạng }\end{array}$ & 39 & 86,7 \\
\hline $\begin{array}{c}\text { Xếp loại } \\
\text { kết quả }\end{array}$ & Tốt & 39 & 86,7 \\
\cline { 2 - 4 } & Trung bình & 6 & 13,3 \\
\hline
\end{tabular}

Kết quả xa (3-6 tháng) một số biến chứng xa như sẹo giãn $>2 \mathrm{~mm}(16,7 \%)$, co kéo hốc tự nhiên mức độ ít $(5,6 \%)$ được theo dõi, đánh giá trong 27/36 nơ vi đã được loại bỏ hoàn toàn thương tổn. 91,6\% trường hợp bệnh nhân và/ hoặc bố mẹ bệnh nhân cảm thấy hài lòng nhiêu, $8,4 \%$ trường hợp hài lòng mức độ trung bình. Xếp loại kết quả đạt tốt với $31 / 36$ (86,1\%) trường hợp, trung bình với 5/36 (13,9\%) trường hợp, không có trường hợp đạt kết quả kém.

\section{BÀN LUẬN}

Chúng tôi đã phân chia nơ vi hắc tố bẩm sinh vùng mặt cổ thành 3 nhóm, theo kích thước, đơn vị giải phẫu thẩm mỹ của mặt và số lân phẫu thuật yêu cầu, theo kết quả nghiên cứu của Gur vàZyker": với nhóm kích thước $\leq 3 \mathrm{~cm}$ thường cần phẫu thuật 1 lần, 3-12cm thường cân 1-2 lần phẫu thuật, $\geq 12 \mathrm{~cm}$ thường cân từ trên 3 lần phẫu thuật. Chúng tôi nhận thấy phân loại này là hữu ích trong việc phân tích các vấn đề và thiết lập ra một kế hoạch phẫu thuật cho cắt bỏ. Đólà cơ sở cho thuật toán của chúng tôi và giảm thiểu số lượng can thiệp cân thiết.

Trong nghiên cứu, nhóm 1 là nơ vi kích thước nhỏ 25/36 bệnh nhân hoàn toàn chỉ 1 lần phẫu thuật và phần lớn loại bỏ hết hoàn toàn nơ vi, phương pháp hay dùng nhiều nhất là giãn da tự nhiên và vạt tại chỗ vì kết quả về màu sắc rất phù hợp so với ghép da. Chú ý về các kỹ thuật này là nên đưa đường sẹo về nếp nhăn tự nhiển hoặc những vùng rìa của đơn vị thẫm mỹ, có thể phối hợp Z-plasty khi có sự cokéo đặc biệt là ở môi và mí mắt, vạt $\mathrm{O}-\mathrm{Z}$ được sử dùng trển một bệnh nhân có nơ vi ở mi trên để tránh tình trạng có kéo của mí và lông mày. Một số phương pháp như cắt theo hình chêm, khi các đâu tận của đường cắt vượt sang 1 đơn vị thẩm mỹ khác của vùng mă̆t thì có thể tạo hình chữ $M$ để rút ngắn chiều dài đường khâu để giảm thiểu sẹo vượt quá ranh giới của các đơn vị thẩm mỹ. Đóng trực tiếp theo các đường căng da kèm theo cắt tai chó cẩn thân thường có thể được dùng ở vùng má, môi, và trán; độ đàn hồi của da những vùng này giúp ngăn ngừa tình trạng co kéo môi, mi mắt, và lông mày ${ }^{7}$, kỹ thuật đơn giản và chi phí thấp.

Nhóm 2 cho thấy kết quả tạo hình phù hợp với giãn da tự nhiên cắt dân,vạt tại chố, vạt kế 
cân. 4/36 bênh nhân phẫu thuật 1 lần và 3/36 phải trải qua 2 lần, nơ vi nhóm này thường nằm $\geq 2$ đơn vi thẫm mỹ và tạo sự khó khắn khi đóng lại thương tổn sau cắt bỏ vì sẽ gây biến dạng co kéo nhiều. Vạt đẩy, vạt xoay, vạt chuyểnđược sử dụng để tránh sự biến dạng của mặt. Vạt kế cận sử dụng trên một bệnh nhân có nơ vi ở lông mày với kỹ thuật vạt da tóc lấy từ thái dương cuống mạch liền nhánh động mạch thái dương nông.

Nhóm 3 là nhóm khó khăn và phức tạp nhất, nơ vi kích thước lớn hoặc khổng lồ, thường có một hình dáng đặc biệt là chiếm một nửa mắt thường gồm chung đớn vi thẩm mỹ như trán, thái dương, quanh mắt, mũi và má. Đổi hỏi kinh nghiệm và lập kế hoạch chặt chẽ trước khi phẫu thuât. Chúng tôicó 4 bênh nhân nằm trong nhóm này. Ghép da dày và vạt tổ chức giãn thường đặt ra trong một số ca, ghép dạ dày là phương pháp thuân lợi cho viêc tái tạo lại khuyết tổn lớn, sử dụng da dày vùng sau tai làm mảnh ghép rất phù hợp về màu sắc với đơn vị mũi và vùng quanh mắt, lưu ý nếu phải ghép da dày nên ghép vào đúng đơn vị thẩm mỹ. Một số trường hợp tổn thương rộng có thể lấy da dày từ bẹn bụng. Trong nghiên cứu này chỉ một bệnh nhẩn sử dụng phương pháp vạt tổ chức giãn, phẫu thuật lần 1 đăt chất liêu giãn da, tiến hành bơm túi giãn 3 tháng phẫu thuật thì 2 tháo túi tạo hình vùng má và trán bằng dạng vạt chuyển và đẩy. Kết quả sau phẫu thuật rất tốt vì màu sắc của vạt giãn tương đồng da xung quanh, nhưng ngược điểm nhiều thì phẫu thuật, kéo dài thời gian điều trị và chi phí của chất liệu vẫn rất cao so với phương pháp tao hình khác.

Trong 45 lần phẫu thuât cho kết quả tốt trong 39 lần $(86,7 \%), 6$ lần $(13,3 \%)$ cho kết quả trung bình và không có trường hợp nào có kết quả kém. 6 trường hợp thiểu dưỡng mép và chậm liền vết mổ xảy ra trong những khối nơ vi có kích thước lớn, mối lần phẩu thuât đều lây bỏ một lượng tổn thương lớn. Do đó vểt mổ sau khi khâu đóng có tình trạng bị căng. Tình trạng co kéo hốc tự nhiên xảy ra ở các khối nơ vi nằm trên nhiều đơn vị giải phẫu của mặt và gần các hốc tự nhiên như mắt, mũi, miệng. Có thể thấy, kết quả phẫu thuật gần hấu hết là liền thương tốt, không có các biến chứng chảy máu, nhiễm trùng hay hoại tử vết mổ, tî lệ co kéo tổ chức không lớn. Như vậy các phương pháp tạo hình chúng ta lựa chọn cho từng bệnh nhân rất có hiệu quả và ít biến chứng.

Kết quả xa được đánh giá trên 36 bệnh nhân, 27 khối nơ vi đã được loại bỏ hoàn toàn tổn thương: kết quả tốt trong 31 trường hợp $(86,1 \%)$, kết quả trung bình trong 5 trường hợp $(13,9 \%)$, không có trường hợp nào cho kết quả kém khi theo dõi xa. Hâuu hết đều có tình trạng sẹo vết mổ đẹp, 6 trường hợp sẹo giãn $>2 \mathrm{~mm}$ cũng chính là 6 trường hợp chậm liên vết mổ do căng khi khâu đóng, 2 trường hợp có sẹo lồi vùng sau tai gặp bệnh nhân lớn tuổi và nơi có cuốn vạt căng kéo ban đầu. 2 trường hợp mất lông mày do cắt bỏ cùng nơ vi và 2 trường hợp da vùng da ghép có màu đậm hơn da thường. Tình trang co kéo các cơ quan cũng giảm từ nhiều thành ít, hoăc từ ít thành không co kéo. Điều này chứng tỏ tính chum giãn của da rất tốt và có thể phục hồi theo thời gian.

\section{KẾT LUÂN}

Điều trị nơ vi hắc tố bẩm sinh vùng mặt cổ đặc biệt những khối nằm trên nhiều đơn vị và kích thước lớn luôn là thách thức với phẫu thuật viên taọ hình. Kỹ thuật đơn giản và dễ dược áp dụng nhất dựa trên đặc tính da giãn tự nhiên áp dụng hiệu quả đối với những khối nhỏ. Ngoài ra, các kỹ thuật vạt tại chỗ, lân cận và vạt da giãn cũng nhiều ưu điểm và thường thích hợp với tổn thương trung bình hoặc lớn. Điều trị cho nơ vi vùng mặt cổ khồng lồ rất cần sự kiên trì của cả bệnh nhân cũng như phẫu thuật viên.

\section{TÀI LIÊU THAM KHẢO}

1. Lyon VB. Congenital melanocytic nevi. Pediatric clinics of North America. Oct 2010. 57(5):11551176. doi:10.1016/j.pcl.2010.07.005.

2. Krengel S; Scope A; Dusza S.W et al. (2013). New recommendations for the categorization of cutaneous features of congenital melanocytic nevi. Journal of the American Academy of Dermatology, 68(3), 441-451.

3. Thuận ĐĐ. Kỹ thuật giãn da tự nhiên trong phẫu thuật tạo hình những tổn thương vùng mặt o trẻ em. Y họ̣c Việt Nam. 2007

4. Nguyễn Hồng Sơn (2010). Nghiên cứu đă̆c điểm lâm sàng và đánh giá kết quả điều trị phẩu thuật nơ vi sắc tố bẩm sinh khổng lồ, Phấu thuật tao hình, Đai hoc Y Hà Nội, Hà Nôi.

5. Lình TTD. Khảo sát đăc điểm Nơovi hắc tố bẩm sinh. 2018. Đại học Y Hà Nội, Hà Nội.

6. David Leshem, MD, EyalGur,MD, Benjamin Meilik,MD, RonaldM. ,MD. (2019). Treatment of congenital facial nevi. Journal of Craniofacial Surgery: September 2005 - Volume 16 - Issue 5 p 897-903

7. Nguyến Bắc Hùng, Phẫu thuật tạo hình. Hà Nội: Nhà xuất bản y học, 2006.

8. Gur E, Zuker RM. Complex facial nevi: a surgical algorithm. Plastic and reconstructive surgery. Jul $2000 . \quad 106(1): 25-35$ doi:10.1097/00006534-200007000-00005. 